\title{
Comparison of single and biplane ejection fractions in patients with ischaemic heart disease ${ }^{1}$
}

\author{
Warren Walsh, Raul E. Falicov, and A. L. Pai \\ From The University of Chicago, Department of Medicine, Section of Cardiology, Chicago, Illinois, U.S.A.
}

Simultaneous biplane left ventriculography was performed in 59 patients with ischaemic heart disease. $A$ comparison was made of the frontal (EFF), lateral (EFL), and biplane (EFB) ejection fractions. Discrepancies between the three measurements in the same patient were frequently observed. The patients were then grouped according to the presence or absence of signs of transmural myocardial infarction in the electrocardiogram or wall motion abnormalities, and the single and biplane EF data were again compared. There were 31 patients with previous transmural myocardial infarction and 37 patients with wall motion abnormalities, usually involving the anterior or inferior walls. The EFL of patients with transmural myocardial infarction or wall motion abnormalities commonly exceeded the EFF, because of frequent preservation of dorsal wall contraction visualized only in the lateral plane. Consequently, there was a significant difference between EFF or EFL and EFB for these patients. In contrast, there was close agreement between EFF and EFL for patients without transmural myocardial infarction or wall motion abnormalities. It is concluded that differences frequently occur between single and biplane EF in patients with ischaemic heart disease, especially if transmural myocardial infarction or wall motion abnormalities are present. Hence, accurate assessment of left ventricular performance is greatly facilitated by simultaneous or sequential biplane ventriculography.

Systolic ejection fraction has recently become an important index of left ventricular performance. It is quoted particularly in the context of coronary artery surgery, where it is used both as a criterion of operability and an index of postoperative myocardial function (Cohn et al., 1974b; Lea et al., 1972). In most cases, the ejection fraction has been calculated from single plane angiograms. Attention is now being drawn to the frequent occurrence of segmental left ventricular wall motion abnormalities in coronary artery disease (Baxley and Reeves, 1971; Cohn, Herman, and Gorlin, 1974) and consequently doubt has been cast on single plane ejection fraction as a reliable index of left ventricular performance (Vogel, Cornish, and McFadden, 1973; Gentzler et al., 1973). We have, therefore, analysed our data obtained from biplane angiography in 59 patients evaluated for angina pectoris or heart failure. An attempt was made to seek any parameter that might predict the accuracy of single plane ejection fraction in the individual patient.

Received 29 September 1975.

${ }^{1}$ This work was supported in part by the Louis B. Block Fund and by USPHS, NHLI Myocardial Infarction Research Unit Contract.

\section{Methods}

Fifty-nine biplane left ventricular (LV) cineangiocardiograms were obtained from patients evaluated for angina pectoris or heart failure in the cardiac catheterization laboratory. All patients had resting electrocardiograms performed before the procedure.

Premedication was with 100 to $200 \mathrm{mg}$ oral pentobarbitone and $0.6 \mathrm{mg}$ atropine given subcutaneously. All patients underwent selective coronary arteriography by the Judkins technique, with multiple oblique views as the initial part of the procedure. After this, the left ventricle was entered with a 'pigtail' catheter and 40 to $60 \mathrm{ml}$ Renografin 76 was injected under pressure into the left ventricular cavity. The ventriculogram was recorded on $35 \mathrm{~mm}$ cine film, in the frontal and lateral projections simultaneously, at 64 frames per second.

The LV cineangiogram was later projected on either a Vanguard rear display or a Tagarno frontal display system. Optimal end-systolic and end-diastolic frontal and their corresponding lateral frames were selected, eliminating both premature ventricular contractions and the first following beat. Biplane ventricular volumes were calculated either by hand planimetry or by a recently developed semiautomated computer system (Pai, Fozzard, and Brooks, 1974). In the former case, the selected ventricular silhouettes were traced, the areas planimetered, and the long axes measured. 
Biplane end-systolic and end-diastolic volumes were then calculated according to the area-length method of Dodge using the formula (Dodge et al., 1960):

$$
\mathrm{V}_{\mathrm{t}}=0.78 \times \frac{\left(\mathrm{CF}_{\mathrm{m}}\right)^{2}\left(\mathrm{CF}_{\mathrm{s}}\right) \mathrm{A}_{\mathrm{a}} \mathrm{A}_{1}}{\mathrm{~L}_{\mathrm{s}}}-3.8
$$

Where $\quad \mathrm{V}_{\mathrm{t}}=$ true biplane volume $(\mathrm{ml})$

$$
\begin{aligned}
\mathrm{CF}_{\mathrm{m}}= & \text { correction factor for non-parallel } x \text {-ray } \\
& \text { distortion on the projection with the } \\
& \text { greatest major axis } \\
\mathrm{CF}_{\mathrm{s}}= & \text { correction factor in the other projection } \\
\mathrm{A}_{\mathrm{a}}= & \text { area of the projected image in the } \\
& \text { anteroposterior view }\left(\mathrm{cm}^{2}\right) \text { uncorrected } \\
\mathrm{A}_{1}= & \text { area of the projected image in the lateral } \\
& \text { view }\left(\mathrm{cm}^{2}\right) \text { uncorrected } \\
\mathrm{L}_{\mathrm{s}}= & \text { the shortest of the two measured long } \\
& \text { axes. }
\end{aligned}
$$

The biplane ejection fraction (EFB) was obtained from the formula:

$$
\mathrm{EFB}=\frac{\mathrm{EDV}-\mathrm{ESV}}{\mathrm{EDV}} \%
$$

Where ESV = end systolic volume

$\mathrm{EDV}=$ end diastolic volume.

Single plane (either frontal or lateral) ejection fraction (EFS) was calculated using the formula:

$$
\mathrm{EFS}=1-\left[\frac{L_{D}}{L_{S}} \times\left(\frac{A_{S}}{A_{D}}\right)^{2}\right] \times 100 \%
$$

Where $\mathbf{L}_{\mathbf{D}}=$ long axis in diastole $(\mathrm{cm})$

$\mathrm{L}_{\mathrm{S}}=$ long axis in systole $(\mathrm{cm})$

$A_{\mathrm{S}}=$ area of projected image in end-systole

$A_{D}=$ area of projected image in end-diastole.

When the computer system was used, a hypersonic Graf-pen digitizer was used to trace the desired ventricular silhouettes and thus enter the digitized left ventricular boundary co-ordinate data into a PDP-11 minicomputer system. The ventricular volume analysis programme displayed the digitized image on a cathode ray storage tube and permitted the image either to be accepted or rejected and retraced. The computer programme then used the ventricular boundary coordinate data to compute the long axis of the left ventricle, area enclosed by LV contour by integration, biplane ventricular volumes using Dodge's formula (a), biplane ejection fraction by formula (b), and single plane ejection fraction using formula (c).

Wall motion analysis was performed by superimposing end-systolic and end-diastolic frames using the midpoint of the aortic valve as the fixed point of reference. This was done either by hand or using the computer generated displays of superimposed digitized systolic and diastolic contours on the storage oscilloscope. The ventricular outline was divided into three segments in each plane: 1) frontal: anterolateral, apical, and inferior; 2) lateral: anterior, inferior, and dorsal. These segments were then examined qualitatively for wall motion abnormalities during systole.

\section{Results}

\section{Angiographic analysis}

The coronary arteriographic, electrocardiographic, and ventriculographic findings for the 59 patients are listed in Tables 1 and 2. Seven patients were normal in all these respects, 51 had coronary artery disease shown on the coronary arteriogram, and one patient had congestive cardiomyopathy with normal coronary arteries.

The distribution of major lesions (greater than $70 \%$ stenosis) in the 51 patients with coronary artery disease was as follows: 82 per cent had major lesions in the left anterior descending artery, 59 per cent in the right coronary artery, and 57 per cent in the main left circumflex coronary artery or one of its lateral branches. Three patients had additional major stenosis of the left main coronary artery.

Thirty-seven patients $(63 \%)$ had wall motion abnormalities on the left ventriculogram. If those patients with normal coronary arteries were excluded, the proportion rose to 73 per cent.

The close relation between wall motion abnormalities and transmural myocardial infarction was shown by the fact that 27 of 31 patients $(87 \%$ ) with electrocardiographic evidence of transmural myocardial infarction showed segmental wall motion abnormalities on the left ventriculogram. The 27 patients comprised all 9 patients with anterior and inferior transmural myocardial infarction, 10 of the 11 patients with anterior transmural myocardial infarction, and 8 of the 11 patients with inferior transmural myocardial infarction. These data contrasted with the low incidence of wall motion abnormalities in patients with normal electrocardiograms or with nontransmural myocardial infarction. Wall motion abnormalities were present in 5 of 18 patients with normal electrocardiograms and 1 of 4 patients with nontransmural myocardial infarction.

Of the 4 remaining patients with wall motion abnormalities, 2 had electrocardiographic criteria for left ventricular hypertrophy and 2 had left bundle-branch block. Both patients with left bundlebranch block had severe triple vessel disease.

The locations of the wall motion abnormalities in these 37 patients are given in Table 1. Abnormalities in the anterior or apical segments were seen in almost all cases. The inferior wall was less commonly involved and the dorsal (or posterior) ventricular wall was the site of wall motion abnormalities in only 33 per cent of the cases. The location of the wall motion abnormality usually corresponded to regions supplied by severely stenotic or occluded coronary arteries. 
TABLE 1 Electrocardiographic, coronary arteriographic, ventriculographic findings and single and biplane ejection fractions of patients with wall motion abnormalities

\begin{tabular}{|c|c|c|c|c|c|c|c|c|c|c|c|c|}
\hline \multirow{2}{*}{ Case No. } & \multirow{2}{*}{ Electrocardiogram } & \multicolumn{4}{|c|}{ Coronary arteriogram * } & \multicolumn{4}{|c|}{ Left ventriculogram† } & \multicolumn{3}{|c|}{ Ejection fraction (\%) } \\
\hline & & $L A D$ & $L C X$ & $R C A$ & $L M C$ & Ant & $A p i$ & $\operatorname{Inf}$ & Dorsal & Biplane & Frontal & Lateral \\
\hline 1 & Anterior (transmural) & 2 & 1 & 2 & 0 & $\mathbf{H}$ & $\mathbf{H}$ & $\mathbf{N}$ & $\mathbf{N}$ & 70 & 59 & 70 \\
\hline 2 & Inferior (transmural) & 2 & 2 & 1 & 0 & $\mathbf{N}$ & $\mathbf{H}$ & $\mathbf{H}$ & $\mathbf{N}$ & 61 & 42 & 70 \\
\hline 3 & Anterior (transmural) & 3 & 0 & 0 & 0 & A & $\mathrm{A}$ & $\mathbf{P}$ & $\mathbf{N}$ & 31 & 27 & 42 \\
\hline 4 & Anterior (transmural) & 3 & 2 & 3 & 0 & $\mathbf{H}$ & A & $\mathbf{H}$ & $\mathbf{N}$ & 36 & 38 & 50 \\
\hline 5 & Anterior (transmural) & 2 & 2 & 2 & 0 & $\mathbf{H}$ & A & $\mathbf{H}$ & $\mathrm{N}$ & 42 & 49 & 40 \\
\hline 6 & Ant-inf (transmural) & 3 & 2 & 2 & 0 & $\mathbf{H}$ & $\mathrm{H}$ & $\mathbf{H}$ & $\mathbf{H}$ & 41 & 28 & 45 \\
\hline 7 & Normal & 0 & 2 & 1 & 0 & $\mathbf{H}$ & $\mathbf{N}$ & $\mathrm{N}$ & $\mathrm{N}$ & 59 & 60 & 55 \\
\hline 8 & Inferior (transmural) & 1 & 3 & 3 & 0 & $\mathbf{H}$ & A & A & $\vec{H}$ & 28 & 33 & 39 \\
\hline 9 & Normal & 0 & 0 & 3 & 0 & $\mathbf{H}$ & $\mathbf{N}$ & $\mathbf{N}$ & $\mathbf{N}$ & 47 & 49 & 43 \\
\hline 10 & Ant-inf (transmural) & 3 & 2 & 2 & 0 & $\mathrm{H}$ & $\mathbf{H}$ & $\mathbf{H}$ & $\mathbf{H}$ & 29 & 21 & 32 \\
\hline 11 & Inferior (transmural) & 2 & 2 & 2 & 0 & $\mathbf{N}$ & $\mathbf{N}$ & $\mathbf{H}$ & $\mathbf{N}$ & 71 & 65 & 73 \\
\hline 12 & Ant-inf (transmural) & 2 & 1 & 0 & 0 & A & A & H & $\mathbf{N}$ & 18 & 07 & 37 \\
\hline 13 & Anterior (transmural) & 3 & 2 & 0 & 0 & A & A & A & $\mathbf{N}$ & 12 & 12 & 17 \\
\hline \multirow[t]{2}{*}{$\begin{array}{l}13 \\
14\end{array}$} & Anterior & & & & & & & & & & & \\
\hline & (non-transmural) & 3 & 0 & 3 & 0 & $\mathbf{H}$ & $\mathbf{H}$ & $\mathbf{H}$ & $\mathbf{H}$ & 14 & 19 & 15 \\
\hline 15 & Normal & 2 & 3 & 1 & 2 & $\mathbf{H}$ & $\mathbf{H}$ & $\vec{H}$ & $\mathbf{N}$ & 59 & 46 & 62 \\
\hline 16 & Inferior (transmural) & 0 & 2 & 3 & $\overline{0}$ & $\mathbf{H}$ & $\mathrm{A}$ & A & $\mathbf{N}$ & 36 & 37 & 47 \\
\hline 17 & Anterior (transmural) & 3 & 1 & 1 & 0 & $\mathrm{H}$ & $\mathbf{P}$ & A & $\mathbf{H}$ & 23 & 37 & 20 \\
\hline 18 & Ant-inf (transmural) & 3 & 3 & 3 & 0 & $\mathrm{H}$ & $\mathbf{H}$ & A & $\mathbf{N}$ & 19 & 19 & 26 \\
\hline 19 & Ant-inf (transmural) & 3 & 1 & 3 & 0 & $\mathbf{N}$ & $\mathbf{H}$ & $\mathbf{H}$ & $\mathbf{H}$ & 27 & 42 & 17 \\
\hline 20 & Inferior (transmural) & 2 & 2 & 1 & 0 & $\mathbf{H}$ & $\mathbf{N}$ & $\mathbf{N}$ & $\mathbf{N}$ & 63 & 58 & 63 \\
\hline 21 & LVH & 0 & 2 & 2 & 0 & A & $\mathbf{H}$ & $\mathbf{H}$ & $\mathbf{N}$ & 32 & 25 & 26 \\
\hline 22 & LBBB & 2 & 2 & 3 & 0 & A & $\mathbf{H}$ & $\mathbf{H}$ & $\mathbf{H}$ & 25 & 29 & 16 \\
\hline 23 & Normal & 2 & 1 & 2 & 0 & $\mathbf{H}$ & $\mathbf{N}$ & $\mathbf{H}$ & $\mathbf{N}$ & 40 & 47 & 44 \\
\hline 24 & Inferior (transmural) & 2 & 3 & 3 & 2 & $\mathbf{A}$ & $\mathbf{H}$ & $\mathrm{H}$ & $\mathrm{H}$ & 38 & 27 & 34 \\
\hline 25 & Ant-inf (transmural) & 3 & 2 & 3 & 0 & $\mathbf{H}$ & $\mathbf{H}$ & A & $\mathrm{H}$ & 25 & 21 & 23 \\
\hline \multirow[t]{2}{*}{26} & Inf (transmural), and & & & & & & & & & & & \\
\hline & ant (non-transmural) & 2 & 2 & 2 & 0 & $\mathbf{N}$ & $\mathbf{N}$ & $\mathbf{H}$ & $\mathbf{N}$ & 72 & 72 & 67 \\
\hline 27 & Anterior (transmural) & 3 & 0 & 1 & 0 & A & $\mathbf{H}$ & $\mathbf{N}$ & $\mathbf{N}$ & 34 & 31 & 54 \\
\hline 28 & LVH & 0 & 0 & 0 & 0 & $\mathbf{A}$ & $\mathrm{H}$ & $\mathbf{H}$ & $\mathbf{H}$ & 21 & 23 & 15 \\
\hline 29 & Ant-inf (transmural) & 2 & 1 & 3 & 0 & $\mathbf{H}$ & $\mathrm{H}$ & $\mathbf{H}$ & $\mathbf{N}$ & 21 & 29 & 35 \\
\hline 30 & Anterior (transmural) & 3 & 1 & 3 & 0 & $\mathbf{H}$ & $\mathbf{H}$ & $\mathrm{H}$ & $\mathbf{H}$ & 30 & 31 & 31 \\
\hline 31 & LBBB & 2 & 2 & 3 & 0 & $\mathbf{A}$ & $\mathbf{H}$ & $\mathbf{H}$ & $\mathbf{N}$ & 08 & 09 & 21 \\
\hline 32 & Anterior (transmural) & 1 & 1 & 3 & 0 & A & $\mathrm{H}$ & $\mathrm{H}$ & $\mathbf{N}$ & 25 & 17 & 45 \\
\hline 33 & Ant-inf (transmural) & 3 & 2 & 1 & 0 & $\mathbf{A}$ & $\mathbf{H}$ & $\mathbf{A}$ & $\mathbf{N}$ & 13 & 14 & 21 \\
\hline 34 & Inferior (transmural) & 2 & 2 & 1 & 0 & $\mathrm{H}$ & $\mathbf{N}$ & $\mathbf{H}$ & $\mathbf{N}$ & 59 & 51 & 61 \\
\hline 35 & Normal & 3 & 0 & 0 & 0 & $\mathbf{H}$ & $\mathbf{N}$ & $\mathbf{N}$ & $\mathbf{N}$ & 75 & 71 & 72 \\
\hline 36 & Anterior (transmural) & 3 & 0 & 1 & 0 & $\mathbf{A}$ & $\mathbf{H}$ & $\mathbf{H}$ & $\mathbf{N}$ & 44 & 36 & 50 \\
\hline 37 & Ant-inf (transmural) & 3 & 2 & 3 & 0 & $\mathbf{H}$ & $\mathrm{H}$ & $\mathrm{H}$ & $\mathbf{H}$ & 47 & 39 & 52 \\
\hline
\end{tabular}

Abbreviations

* Coronary arteriogram: LAD = left anterior descending artery, LCX = left circumflex artery, RCA $=$ right coronary artery, LMC = left main coronary artery, $3=$ occlusion, $2=>70$ per cent stenosis, $1=<70$ per cent stenosis, $0=$ normal.

+ Left ventriculogram: Ant $=$ Anterior, $A$ pi $=$ Apical, Inf $=$ Inferior, $\mathbf{N}=$ normal, $\mathbf{H}=$ hypokinesia, $A=$ akinesia, $P=$ paradoxical.

\section{Ejection fraction analysis}

Table 3 lists the mean single and biplane ejection fractions for all patients and for the subgroups with or without previous transmural myocardial infarction or wall motion alnormalities. Patients with a history of previous myocardial infarction or with documented wall motion abnormalities tended to have low ejection fractions, while those without these features tended to have normal ejection fractions.

The single and biplane ejection fraction data for each patient are given in Tables 1 and 2. Compari- son of frontal (EFF), lateral (EFL), and biplane (EFB) ejection fractions for the same patients frequently revealed significant differences between frontal and lateral plane measurements and between single and biplane measurements.

The data were subjected to further analysis in an effort to explain these discrepancies. Each case was examined for the presence or absence of electrocardiographic evidence of transmural myocardial infarction, and of wall motion abnormalities. The results are presented in Tables 1 and 2 and displayed graphically in Fig. 1 and 2. 
A consistent discrepancy between frontal and lateral plane measurements in patients with either transmural myocardial infarction or wall motion abnormalities was observed. In most cases higher values were obtained for the lateral plane than for the frontal plane measurement. The mean EFF for patients with myocardial infarction was $39.7 \pm 3.8$ per cent and the mean EFL was $46.7 \pm 3.7$ per cent $(P<0.0025)$. Similarly, the mean EFF for patients with wall motion abnormalities was $35.5 \pm 2.8$ per cent, while the mean EFL was $41.5 \pm 3.0$ per cent $(P<0.005)$.

Biplane ejection fractions tended to be intermediate between the frontal plane and the lateral plane ejection fraction in the patients with myocardial infarction or wall motion abnormalities. The differences between EFF or EFL and EFB for these groups were statistically significant (Table 3).

Differences between single and biplane ejection fractions were also seen in patients with no previous myocardial infarction or whose ventriculograms showed no abnormally contracting segments. However, when the magnitude and the range of differences between single and biplane measurements for these patients were examined, both smaller discrepancies and less scatter of values were noted. These observations are illustrated graphically in Fig. 1 and 2, where biplane ejection fraction is plotted against frontal and lateral plane ejection fraction respectively. The standard error for the regression (Syx) of EFB on EFF of the patients with myocardial infarction or wall motion abnormalities was in both cases $7 \cdot 8$. Patients without either of these features had considerably smaller

TABLE 2 Electrocardiographic, coronary arteriographic findings and single and biplane ejection fractions of patients without wall motion abnormalities

\begin{tabular}{|c|c|c|c|c|c|c|c|c|}
\hline \multirow{2}{*}{ Case No. } & \multirow{2}{*}{ Electrocardiogram } & \multicolumn{4}{|c|}{ Coronary arteriogram } & \multicolumn{3}{|c|}{ Ejection fraction (\%) } \\
\hline & & $L A D$ & $L C X$ & $R C A$ & $L M C$ & Biplane & Frontal & Lateral \\
\hline 38 & Normal & 0 & 0 & 0 & $\mathbf{0}$ & 79 & 72 & 80 \\
\hline 39 & Normal & 0 & 0 & 0 & 0 & 90 & 90 & 86 \\
\hline 40 & Anterior (non-transmural) & 2 & 2 & 2 & 0 & 77 & 75 & 75 \\
\hline 41 & Anterior (non-transmural) & 1 & 0 & 0 & 0 & 87 & 84 & 86 \\
\hline 42 & Normal & 2 & 0 & 1 & 0 & 80 & 78 & 81 \\
\hline 43 & Normal & 2 & 2 & 2 & 0 & 86 & 85 & 83 \\
\hline 44 & Normal & 2 & 3 & 1 & 0 & 79 & 81 & 75 \\
\hline 45 & Normal & 2 & 1 & 1 & 0 & 60 & 65 & 62 \\
\hline 46 & Inferior (transmural) & 2 & 0 & 2 & 0 & 77 & 74 & 72 \\
\hline 47 & Normal & 0 & 0 & 0 & 0 & 70 & 75 & 57 \\
\hline 48 & Normal & 0 & 0 & 0 & 0 & 83 & 75 & 88 \\
\hline 49 & Anterior (transmural) & 3 & 1 & 1 & 0 & 74 & 72 & 78 \\
\hline 50 & Normal & 2 & 1 & 0 & 0 & 84 & 79 & 81 \\
\hline 51 & Normal & 2 & 1 & 0 & 1 & 75 & 79 & 71 \\
\hline 52 & Normal & 0 & 0 & 0 & 0 & 66 & 60 & 67 \\
\hline 53 & Normal & 1 & 1 & 0 & 2 & 80 & 83 & 75 \\
\hline 54 & RBBB & 0 & 0 & 0 & 0 & 72 & 70 & 66 \\
\hline 55 & LVH & 0 & 2 & 3 & 0 & 90 & 84 & 91 \\
\hline 56 & Inferior (transmural) & 2 & 2 & 3 & 0 & 91 & 85 & 91 \\
\hline 57 & Anterior (non-transmural) & 2 & 2 & 3 & 0 & 84 & 79 & 84 \\
\hline 58 & Inferior (transmural) & 2 & 2 & 2 & 0 & 82 & 84 & 72 \\
\hline 59 & Normal & 0 & 0 & 0 & 0 & 82 & 80 & 79 \\
\hline
\end{tabular}

Abbreviations as in Table 1.

TABLE 3 Mean value of single and biplane ejection fractions for different patient subgroups

\begin{tabular}{|c|c|c|c|c|c|c|c|}
\hline & No. & $E F B$ & $E F F$ & $E F L$ & $\begin{array}{l}E F B \\
\text { vs. } E F F\end{array}$ & $\begin{array}{l}E F B \\
\text { vs. EFL }\end{array}$ & $\begin{array}{l}E F F \\
\text { vs. } E F L\end{array}$ \\
\hline All & 59 & $53 \cdot 3( \pm 3 \cdot 3)$ & $51 \cdot 3( \pm 3 \cdot 2)$ & $54 \cdot 8( \pm 3 \cdot 0)$ & $P<0.0125$ & NS & $\mathbf{P}<0.01$ \\
\hline $\begin{array}{l}\text { Transmural myocardial infarction } \\
\text { No transmural myocardial infarction }\end{array}$ & $\begin{array}{l}31 \\
26\end{array}$ & $\begin{array}{l}42 \cdot 3( \pm 4 \cdot 0) \\
70 \cdot 3( \pm 3 \cdot 7)\end{array}$ & $\begin{array}{l}39 \cdot 7( \pm 3 \cdot 8) \\
68 \cdot 6( \pm 3 \cdot 6)\end{array}$ & $\begin{array}{l}46 \cdot 7( \pm 3 \cdot 7) \\
68 \cdot 2( \pm 3 \cdot 9)\end{array}$ & $\begin{array}{l}P<0.01 \\
P<0.05\end{array}$ & $\begin{array}{l}\mathrm{P}<0.005 \\
\mathrm{P}<0.01\end{array}$ & $\begin{array}{l}\mathbf{P}<0.0025 \\
\text { NS }\end{array}$ \\
\hline $\begin{array}{l}\text { Wall motion abnormalities } \\
\text { No wall motion abnormalities }\end{array}$ & $\begin{array}{l}37 \\
22\end{array}$ & $\begin{array}{l}37.5( \pm 3.0) \\
79.5( \pm 1 \cdot 7)\end{array}$ & $\begin{array}{l}35.5( \pm 2.8) \\
77.7( \pm 1.5)\end{array}$ & $\begin{array}{l}41.5( \pm 3.0) \\
77.3( \pm 1.9)\end{array}$ & $\begin{array}{l}P<0.05 \\
P<0.025\end{array}$ & $\begin{array}{l}\mathbf{P}<0.005 \\
P<0.025\end{array}$ & $\begin{array}{l}P<0.005 \\
\text { NS }\end{array}$ \\
\hline
\end{tabular}



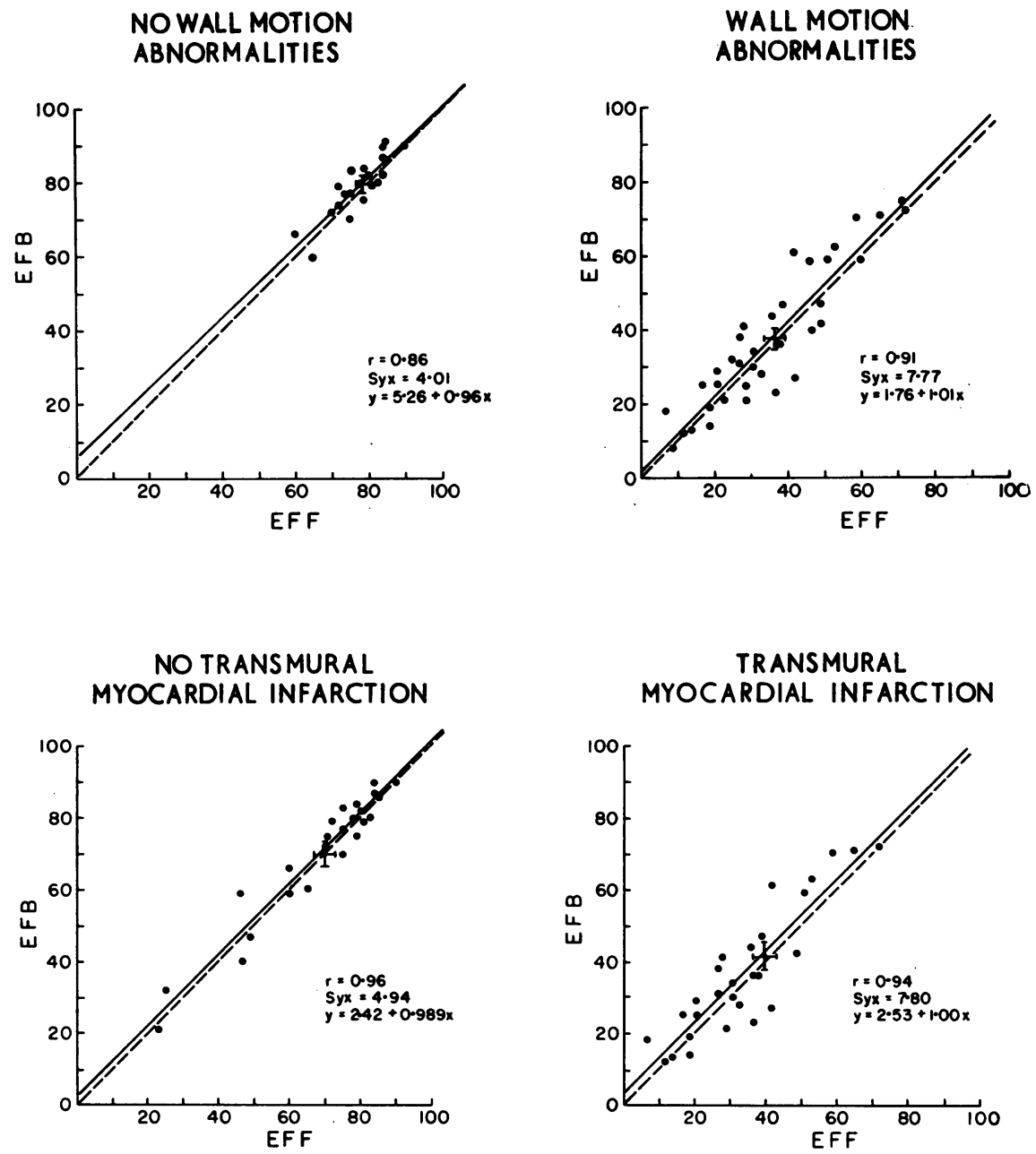

FIG. 1 Relation between the frontal plane and biplane ejection fractions in patients with and without wall motion abnormalities, and with and without the electrocardiographic pattern of previous transmural myocardial infarction. The mean and standard error of the mean are

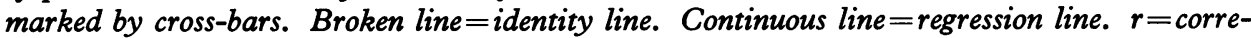
lation coefficient. Syx=standard error of the regression.

standard errors of 4.9 and 4.0 , respectively. Similarly, the standard error for the regression of EFB on EFL for patients with myocardial infarction and for patients with wall motion abnormalities was 8.0. In contrast patients without previous infarction and without wall motion abnormalities had standard errors of 3.8 and 3.7 respectively.

\section{Discussion}

A strong relation between electrocardiographic evidence of transmural myocardial infarction ( $Q$ waves present) and the presence of regional wall motion abnormalities has been confirmed in this series (Miller et al., 1975; Williams et al., 1973). Areas of myocardial necrosis or fibrosis are unable to shorten normally resulting in akinetic or dyskinetic segments. Though $\mathrm{Q}$ waves are a generally reliable predictor of wall motion abnormalities, the absence of $Q$ waves or even a normal electrocardiogram did not exclude the presence of regional wall motion abnormalities in a small number of patients.

It will be seen from the data presented that 
single plane EF may be a poor predictor of biplane EF in patients with coronary artery disease. Only in the group of patients without previous transmural myocardial infarction or wall motion abnormalities was there a reasonable correlation between single plane and biplane EF.

The difference between single plane and biplane $\mathrm{EF}$ in the series as a whole resulted directly from the often large differences between frontal plane EF and lateral plane EF in those patients with previous myocardial infarction and/or wall motion abnormalities. In both groups the lateral plane EF usually exceeded the frontal plane EF.

Why may there be such a discrepancy between frontal and lateral plane ejection fractions? The

NO WALL MOTION

ABNORMALITIES

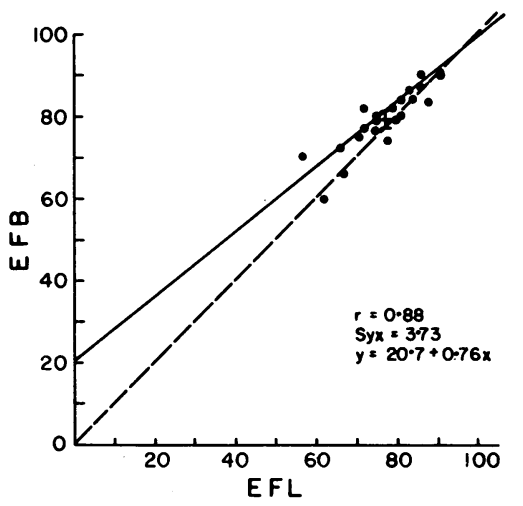

NO TRANSMURAL MYOCARDIAL INFARCTION

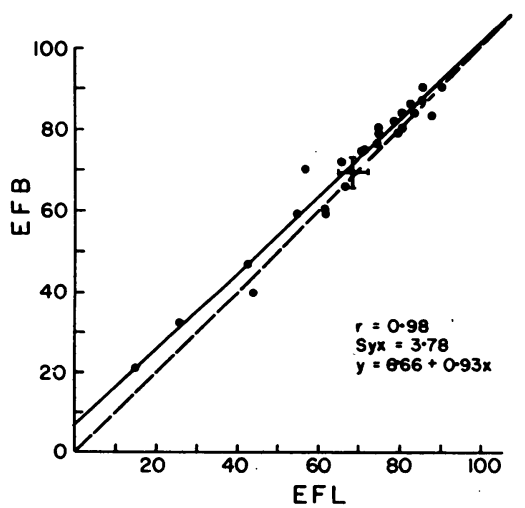

explanation lies in the relation between the particular segment of the left ventricle viewed angiographically and its corresponding arterial blood supply. It has been noted that the left anterior descending and right coronary artery are the most commonly diseased coronary arteries (Proudfit, Shirey, and Sones, 1967). These arteries supply the anterolateral, apical, and inferior walls of the left ventricle, which are best represented on the frontal plane or shallow right anterior oblique ventriculogram. The blood supply of the dorsal wall of the left ventricle is usually from the main circumflex coronary artery and its atrioventricular branch. Abnormally contracting segments are less common in the dorsal wall because of its proximal
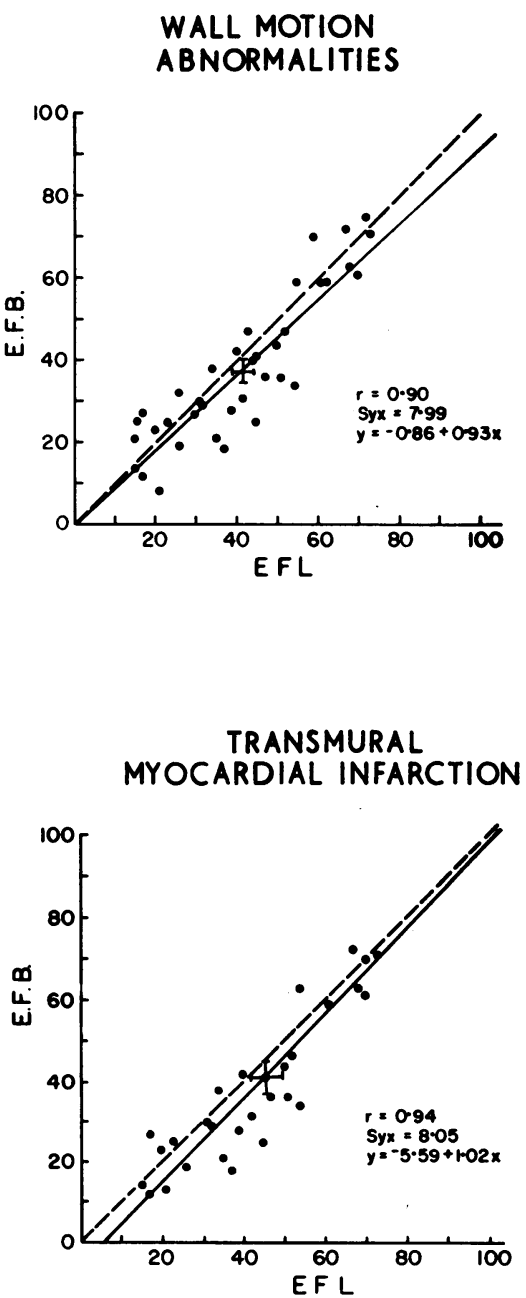

FIG. 2 Relation between the lateral and biplane ejection fractions in the same groups of patients as in Fig. 1. 
blood supply, the lower incidence of atherosclerotic lesions in the circumflex artery, and the frequent presence of proximal collateral circulation. The dorsal wall of the left ventricle hardly appears in the frontal or shallow right anterior oblique projection, but is seen well in the lateral view. Therefore the contribution of a well-contracting dorsal wall to left ventricular ejection will tend to increase the lateral plane EF which therefore exceeds the frontal plane EF in patients with wall motion abnormalities.

For similar reasons, transmural infarction is far more common in the anteroseptal, anterolateral, and inferior walls, than in the dorsal wall of the left ventricle. Because transmural myocardial infarction is strongly associated with wall motion abnormalities in the infarcted region, patients with transmural myocardial infarction will also tend to show this difference between single and biplane EF. This observation has clinical importance, because it suggests that it is possible to predict, before catheterization, a group of patients where one single plane LV angiogram alone may not provide an accurate index of left ventricular performance. In these patients, reliable evaluation of left ventricular performance would require either a second angiogram in a different plane or simultaneous biplane angiography.

An example of the clinical significance of ejection fraction data presented is given by Case 2 (Table 1 ). This patient, who had previously sustained a transmural inferior myocardial infarction, had angina. The coronary angiograms showed major two-vessel disease and the left ventriculogram showed a large abnormally contracting inferoapical segment. Since the clinical decision whether this patient was suitable for coronary artery surgery depended not only on the severity of his symptoms and the state of his distal coronary arteries, but also on the left ventricular performance as a major determinant of operative risk, the latter was assessed by measurement of the ejection fraction. This patient had a frontal plane ejection fraction of 42 per cent. If only the frontal EF was available it might have been concluded that the operative risk was too high and that therefore medical management of his angina might be preferable. However, the lateral plane EF was within normal limits at 70 per cent, and the calculated biplane EF was 61 per cent. With this additional information a more accurate assessment of ventricular performance was available when the selection of surgical or medical therapy was made in this individual patient.

Differences between single plane and biplane volume and ejection fraction measurements have recently been reported by three other groups. Cohn et al. (1974a) compared single plane $30^{\circ}$ right anterior oblique (RAO) ventriculograms with biplane ventriculograms taken $30^{\circ} \mathrm{RAO}$ and $60^{\circ}$ left anterior oblique (LAO). They found a good correlation between single plane and biplan. measurements for the minor diameters, ventricular volumes, and ejection fractions, in patients with and without coronary disease who had normally contracting ventricles. This relation was not so apparent in the patients with ventricular wall motion abnormalities, where there was a wider scatter of values for these parameters. The $60^{\circ}$ LAO provides a similar view of the ventricle to the lateral projection and thus gives an indication of inferoseptal and dorsal wall contraction not seen in the RAO. Vogel et al. (1973) also compared single plane RAO $30^{\circ}$ ventriculograms with biplane ventriculograms in RAO $30^{\circ}$ and LAO $60^{\circ}$ projections. They particularly noted frequent underestimation of the ejection fraction in the RAO projection compared with the biplane measurement in patients with coronary artery disease. This is in agreement with our results. They also pointed out that erroneous conclusions concerning the efficacy of myocardial revascularization could be drawn if pre- and postoperative single plane ejection fractions were compared in the same patient. In some patients single plane EF improved but biplane EF deteriorated; the converse was also seen. Gentzler and his colleagues (1973) compared single plane volume and ejection fraction measurements calculated from the frontal and lateral plane projections in patients with myocardial infarction. Their results obtained differed from our data and those of Vogel et al. (1973); in their patients the lateral ejection fraction was considerably less than the frontal ejection fraction. Furthermore, the measured extent of minor equatorial fibre shortening was also less in the lateral plane. The reason for these conflicting results is not clear from the data presented.

\section{Conclusions}

It may be concluded on the basis of the data presented that: 1) in the absence of wall motion abnormalities or previous myocardial infarction there is a close correlation between ejection fractions measured in the frontal and lateral planes; 2 ) in the presence of wall motion abnormalities or a previous transmural myocardial infarction, the ejection fraction measured in the lateral plane usually exceeds that measured in the frontal plane and, consequently, the frontal plane EF tends to underestimate and the lateral plane EF to over- 
estimate biplane ejection fraction; and 3) accurate angiographic assessment of ventricular performance in patients with coronary artery disease is greatly facilitated by simultaneous or sequential biplane ventriculography, especially if there is electrocardiographic evidence of previous myocardial infarction.

\section{References}

Baxley, W. A., and Reeves, T. J. (1971). Abnormal regional myocardial performance in coronary artery disease. Progress in Cardiovascular Diseases, 13, 405.

Cohn, P. F., Gorlin, R., Adams, D. F., Chahine, R. A., Vokonas, P. S., and Herman, M. V. (1974a). Comparison of biplane and single plane left ventriculograms in patients with coronary artery disease. American fournal of Cardio$\log y, 33,1$.

Cohn, P. F., Gorlin, R., Cohn, L. H., and Collins, J. J. (1974b). Left ventricular ejection fraction as a prognostic guide in surgical treatment of coronary and valvular heart disease. American fournal of Cardiology, 34, 136.

Cohn, P. F., Herman, M. V., and Gorlin, R. (1974). Ventricular dysfunction in coronary artery disease. American Fournal of Cardiology, 33, 307.

Dodge, H. T., Sandler, H., Ballew, D. W., and Lord, J. D. (1960). The use of biplane angiocardiography for the measurement of left ventricular volume in man. American Heart fournal, 60, 762.

Gentzler, R. D., Gault, J. H., Hunter, A. S., Liedtke, A. J., and Leaman, D. M. (1973). Asymmetric left ventricular contraction in patients with previous myocardial infarction. Circulation, 48, 352.

Lea, R. E., Tector, A. J., Flemma, R. J., Johnson, W. D., Beddingfield, G. W., and Leplay, D. (1972). Prognostic significance of a reduced left ventricular ejection fraction in coronary artery surgery. Circulation, 46, Suppl. II, p. 49.

Miller, R. R., Amsterdam, E. A., Bogren, H. G., Massumi, R. A., Zelis, R., and Mason, D. T. (1974). Electrocardiographic and cineangiographic correlations in assessment of the location, nature and extent of abnormal left ventricular segmental contraction in coronary artery disease. Circulation, 49, 447.

Pai, A. L., Fozzard, H. A., and Brooks, H. L. (1974). Computer analysis of left ventricular volumes. Decuscope, $13,3$.

Proudfit, W. L., Shirey, E. K., and Sones, F. M., Jr. (1967). Distribution of arterial lesions demonstrated by selective cinecoronary arteriography. Circulation, 36, 54.

Vogel, H. H. K., Cornish, D., and McFadden, R. B. (1973). Underestimation of ejection fraction with singleplane angiography in coronary artery disease: role of biplane angiography. Chest, 64, 217.

Williams, R. A., Cohn, P. F., Vokonas, P. S., Young, E., Herman, M. V., and Gorlin, R. (1973). Electrocardiographic, arteriographic and ventriculographic correlations in transmural myocardial infarction. American fournal of Cardiology, 31, 595.

Requests for reprints to Dr. Raul E. Falicov, The University of Chicago, Cardiology Section-Box 427, 950 East 59th Street, Chicago, Illinois 60637, U.S.A. 